\title{
Rate of initial highly active anti-retroviral therapy regimen change and its predictors among adult HIV patients at University of Gondar Referral Hospital, Northwest Ethiopia: a retrospective follow up study
}

Degefaye Zelalem Anlay ${ }^{1 *}$, Zinahbizu Abay Alemayehu ${ }^{2}$ and Berihun Assefa Dachew ${ }^{3}$

\begin{abstract}
Background: Regimen change is a major challenge for the sustainability of human immunodeficiency virus (HIV) treatment program. In a resource limited setting where treatment options are limited, designing strategies to increase the durability of original regimen are essential. However, information's on rate of initial regimen change and its predictors is scarce in Ethiopia. Therefore, the purpose of this study was to assess the rate of initial highly active anti retroviral therapy (HAART) regimen change and its predictors among adult HIV patients at the University of Gondar Referral Hospital, Northwest Ethiopia.

Methods: An institutional based retrospective follow up study was conducted among 410 adult HIV patients started HAART from January 2010 to December 2014. Simple random sampling technique was used to select patient records using computer generated random number. Data were collected from patient chart using data extraction tool. The Kaplan-Meier curve was used to estimate the median duration of regimen change. Life table was used to estimate the cumulative survival for initial regimen change and log rank test to compare regimen change survival curves between the different categories of explanatory variables. Bivariate and multivariate Cox proportional hazard model were used to identify predictors of initial regimen change.
\end{abstract}

Results: The overall incidence rate of initial regimen change was 10.11 (95\% Cl 8.29, 12.6) per 100 person years (PY). Baseline WHO clinical stage III (AHR $=1.92,95 \% \mathrm{Cl} 1.12-3.35$ ), occurrence of tuberculosis (TB) on the initial regimen $(A H R=8.33,95 \% \mathrm{Cl} 4.47-15.53)$, side effect on the initial regimen ( $\mathrm{AHR}=25.27,95 \% \mathrm{Cl} 15.12-42.00)$ and co-medication with ART (AHR $=2.5,95 \% \mathrm{Cl} 1.46-4.34$ ) were significant predictors of initial regimen change.

Conclusions: The rate of initial HAART regimen change was found to be high. Having WHO clinical stage III, cOmedication with ART, occurrence of tuberculosis and side effect on initial regimen were independent predictors of regimen change. Hence, close follow-up and screening of patient for side effect and tuberculosis is important.

Keywords: Gondar, HIV infection, Rate, Regimen change, Survival analysis

\footnotetext{
*Correspondence: degefaye@gmail.com

${ }^{1}$ Department of Nursing, College of Medicine and Health Science,

University of Gondar, Gondar, Ethiopia

Full list of author information is available at the end of the article
} 


\section{Background}

The survival of HIV patient increased due to the scale up of antiretroviral therapy and changed HIV infection into chronic conditions. However, changes in treatment and poor adherence limit the therapeutic success of original regimen and sustainability of HIV treatment program since antiretroviral therapy is a lifelong therapy. As far as there is virological success, the initial regimen continues unless the need of regimen changes due to drug side effect, co-morbid illness, pregnancy and other conditions [1-3].

Improving the long term access and sustainability of HIV treatment program by optimizing the limited available combined anti-retroviral regimen is vital. Successive regimens are inferior to that of the original regimen in related to effectiveness and duration. In addition to this; regimen change result in a number of challenges, reduce both the duration and the chance of viral control due to cross resistance between different alternative drug and overlapping toxicity between and within a class of antiretroviral (ARV) drug. Subsequently, the likelihood that successful HAART will last life time is poor $[1,2,4$, 5]. Besides, second line ART is more expensive than that of first line HAART [6].

A multi-center study in North America and Europe showed that the incidence of regimen change were 14.4/100 person years (PY) [7]. Furthermore, 13.8/100PY in Thailand [8], 41.5/100PY in Swiss [9], 28.3/100PY in Brazil [10], 16.2/100PY in West Africa [11], 18.6/100PY in Kenya [12] and the proportion of regimen change in Ethiopia was $21.8 \%$ [13]. Different studies revealed that baseline regimen $[1,12,14]$, WHO stage [12, 15], CD4 count $[6,16,17]$ and patient weight $[12,15]$ were some predictors of initial regimen change.

In resource limited setting including Ethiopia where treatment options are limited; designing strategies to increase the durability of original regimen is essential. So as to achieve this goal, it is important to determine the rate and predictors of initial HAART regimen change. However, information's on rate of initial HAART regimen change and its predictor in Ethiopia is scarce. Therefore, this study was aimed to determine the rate of initial HAART regimen change and its predictor among adult HIV patients. Results from this study will help to design appropriate measures to increase the duration of original regimen among patients on antiretroviral therapy (ART) which subsequently preserve the future treatment options.

\section{Methods}

\section{Study design and setting}

Institution based retrospective follow up study was conducted to determine the rate of initial HAART regimen change and it's predictor among adult HIV patients at University of Gondar Referral Hospital, North West Ethiopia, from January 2010 to June 2015. The study was conducted at Gondar University Hospital ART clinic from May 25 to June 10 2015. University of Gondar Referral Hospital is a teaching Hospital which serves more than five million people of the North Gondar zone and peoples from the neighboring zones. The HIV care service of the Hospital was initiated in 2005 and has 7 outpatient rooms, one voluntary testing and counseling room, one pharmacy, and one laboratory. Since 2005 in which the hospital started ART, 7581 adults and 738 pediatrics patients are enrolled to the HIV care. Currently 4891 adults are actively following their treatment.

Standardized monitoring and evaluation tool and the data collection and management process are well organized and supported by electronic data base system of the hospital. During the study period, based on Ethiopian FMOH update for ART initiation criteria for adult and adolescent patients, the ART initiation criteria were either the CD4 count $350 \mathrm{cell} / \mathrm{mm}^{3}$ or when WHO stage III and IV disease. The choice of ART drug is based on baseline clinical (history and physical examination) and laboratory results (HGB, Liver function test, renal function test). The first line regimen consisted of NRTI backbone zidovudine (AZT) or Stavudine (d4T) or Tenofovir (TDF) or Abacavir (ABC) with Lamivudine (3TC) and either Efavirenz (EFV) or Nevirapine (NVP). Of which the preferred first line drug is TDF-3TC-EFV and the alternative first line regimen are $\mathrm{ZDV}+3 \mathrm{TC}+\mathrm{EFV}, \mathrm{ZDV}+3 \mathrm{TC}+\mathrm{NVP}$ and TDF-3TC-EFV. After initiation of therapy the patient is appointed at 2 weeks, at 1 month, and every month for the first 6 months and then after ever 3 months. Monitoring is done through CD4 count at baseline, every 6 months but only for exceptional case viral load is done specially to assure treatment failure suspected case.

\section{Definition of initial regimen change}

Initial regimen change defined as, a switch or substitution of at least one drug from the original HAART regimen. Regimen change, which is defined in this study, as an event, through the follow up period was ascertained retrospectively when the patients is recorded as changed their regimen and start other HAART drug. According to 2008 Ethiopian federal ministry of health ART guideline which was adopted from WHO guideline; the reasons for treatment change were based on the occurrence toxicity (grade III and IV), tuberculosis, pregnancy, treatment failure and others. Treatment failure was defined as immunological failure (fall of CD4 count to pre-Rx baseline or below or $50 \%$ fall from the on-treatment peak value or persistent CD4 levels below 100 cells $/ \mathrm{mm}^{3}$ ), clinical failure (new or recurrent WHO stage 4 condition) or virological failure (plasma VL 
above $10,000 \mathrm{c} / \mathrm{ml}$ for study period). Patients with the first date of lost to follow up, transfer out, death before the end of the follow up period and completed the follow up period without developed the event were considered as censored.

\section{Inclusion criteria}

All patients aged 15 and above who were started HAART at University of Gondar Hospital, from 1st January 2010 to 31st December 2014. Within this period a total of 2521 and out of whom 410 patients record were reviewed.

\section{Sample size and sampling technique}

The sample size was determined by using single population proportion formula through EPI INFO Stat Calc program with the assumption of $95 \%$ level of confidence, $4 \%$ of marginal error, and taking prevalence of regimen change $21.8 \%$ [18]. With this consideration the final sample size became 410. Patient's chart numbers were taken from the electronic data base as a sampling frame. From a total of 2521 patients who were started HAART 410 charts were selected and reviewed by simple random sampling technique through computer generated random number.

\section{Data collection tools and procedures}

The available information on the patient records had been first observed and appropriate data extraction format was prepared in English. Then the data were collected by four nurses who had ART training using the prepared data collection format on the already existing records after half day theoretical and half day practical training given. One data clerk also supported them by identifying the charts. Charts were retrieved using the patient registration number which was found in the data base in the electronic system.

\section{Data quality control}

Quality of data was maintained by recruiting data collectors who had taken ART training. The data collectors were given intensive training for one day before the data collection about the objective of the study and how to retrieve data for this study purpose using the data extraction format. They briefed on the definition of variables on the questionnaires and registration charts. The data extraction tool was pre-tested for consistency of understanding the review tools, and completeness of data items on 21 charts at the same facility as it was a secondary data and the necessary amendment were made on the final data extraction format. The retrieval process was closely monitored by the principal investigator throughout the data collection period. Completed questionnaires were checked regularly for completeness of information and any gaps identified were immediately communicated to the data collectors.

\section{Data processing and analysis}

After the data were checked for its consistency and completeness, it was entered to EPI-INFO version 7.0 then exported to SPSS version 20 for cleaning and analysis. Summary statistics were carried out to describe the demographics, baseline and follow up data. Incidence density rate (IDR) was calculated for the entire study period. To calculate rate of regimen change among peoples on ART, the total duration of follow up for the whole cohort in person year (PY) was used. The follow up duration for peoples on ART who did not change their regimen was calculated from the time of initiation of ART until the last visit. For those who are changing their regimen; the follow up duration was calculated from initiation of HAART to a substitution of at least one drug from the original regimen. Subsequently, the number of cases who changes their regimen within the cohort was divided by the total regimen change free follow up duration and reported per 100PY.

The survival analysis technique was carried out, as this study has considered time-to-event data, Cox proportional hazard model was fitted, and a life table was used to estimate cumulative probabilities. The KaplanMeier curve was used to estimate the median duration of regimen change. Log rank test was used to compare survival curves between the different categories of the explanatory variables. Both bivariate and multivariate Cox proportional hazard model were used to identify the predictors. Variables with $\mathrm{p}$ value $<0.2$ in the bivariate analysis were entered into the multivariate proportional hazard model. $95 \% \mathrm{CI}$ of hazard ratio was computed and variable having $\mathrm{p}$ value $<0.05$ in the multivariate Cox proportional hazards model was considered as significantly and independently associated with the dependent variable. Cox proportional hazard model fitness was checked using schoenfield residual test.

\section{Ethical statement}

Ethical clearance was obtained from the Institutional Review Board (IRB) of the University of Gondar. Permission letter was obtained from the clinical director of the Hospital. The HIV care clinic head gave the consent for extracting data from records. The confidentiality of the patient was ensured by avoiding name and identification number from extracting.

\section{Results}

Socio-demographic, baseline clinical and immunological status of the respondents

Four hundred ten records were analyzed. The mean age at the initiation of ART was $33.3 \pm 8.7$ years and $181(44.1 \%)$ of the participant were in the age group between 25 and 34 years. More than half of the respondents 265 (64.6\%) were female and majority 363 (88.5\%) 
of them were Orthodox Christian. Regarding the level of education 123 (30\%) of the respondents were completed secondary education. The majority 337 (82.2\%) of the respondents were urban dwellers. A total of 372 (90.7 \%) patients had disclosed their HIV status to either their family or other relatives. Three hundred fifty nine $(87.6 \%)$ did not use any type substance (Table 1$)$.

The majority of the participants, $376(91.7 \%)$ were eligible to HAART by CD4 count of which 56 (13.6\%) were

Table 1 Baseline socio demographic characteristics of HIV positive adults at initiation of HAART at University of Gondar Referral Hospital, January 2010 to December $2014(n=410)$

\begin{tabular}{|c|c|c|}
\hline Characteristics & Frequency & Percentage (\%) \\
\hline \multicolumn{3}{|l|}{ Age } \\
\hline $15-24$ & 51 & 12.4 \\
\hline $25-34$ & 181 & 44.1 \\
\hline $35-44$ & 126 & 30.7 \\
\hline$\geq 45$ & 52 & 12.7 \\
\hline \multicolumn{3}{|l|}{ Sex } \\
\hline Female & 265 & 64.6 \\
\hline Male & 145 & 35.4 \\
\hline \multicolumn{3}{|l|}{ Marital status } \\
\hline Married & 186 & 45.4 \\
\hline Divorced & 96 & 23.4 \\
\hline Single & 73 & 17.8 \\
\hline Widowed & 31 & 7.6 \\
\hline Separated & 24 & 5.9 \\
\hline \multicolumn{3}{|l|}{ Religion } \\
\hline Orthodox & 363 & 88.5 \\
\hline Muslim & 39 & 9.5 \\
\hline Protestant & 6 & 1.5 \\
\hline Catholic and Jewish & 2 & 0.4 \\
\hline \multicolumn{3}{|l|}{ Level of educational } \\
\hline Not educated & 127 & 31 \\
\hline Primary & 102 & 24.9 \\
\hline Secondary & 123 & 30 \\
\hline Tertiary & 58 & 14.1 \\
\hline \multicolumn{3}{|l|}{ Occupation } \\
\hline Unemployed & 326 & 79.52 \\
\hline Employed & 84 & 20.48 \\
\hline \multicolumn{3}{|l|}{ Residence } \\
\hline Urban & 337 & 82.2 \\
\hline Rural & 73 & 17.8 \\
\hline \multicolumn{3}{|l|}{ Disclosure status } \\
\hline Disclosed & 372 & 90.7 \\
\hline Not disclosed & 38 & 9.3 \\
\hline \multicolumn{3}{|l|}{ Substance use } \\
\hline No & 359 & 87.6 \\
\hline Yes & 51 & 12.4 \\
\hline
\end{tabular}

also eligible clinically. The mean weight of the Participant was $53.58 \pm 9.55 \mathrm{~kg}$. The predominant HAART regimen initially prescribed for them were a combination of zidovudine, Lamivudine and Nevirapine (AZT-3TC-NVP), 177 (43.2 \%) followed by Tenofovir, Lamivudine and Efavirenz (TDF-3TC-EFV) for 147 (35.9\%) cases.

More than half 221 (53.9\%) of participants, were initiated on NVP based regimen. Nearly half 201 (49\%) of the patients were started by taking two ART pills/day and 401 (97.8\%) of the participant were taking CPT prophylaxis. One hundred seventy two (42\%) were WHO clinical stage III at the initiation of HAART. The majority, 361 (88 \%) of the participant were on working functional status at a baseline. The median CD4 count at initiation of HAART and the end of follow up was 162.5 [IQR 90.5-235.5] and 291 [IQR 170-433] respectively. Nearly half, 192 (46.8\%) of study subjects were started HAART at HGB level of $\geq 13 \mathrm{~g} / \mathrm{dl}$. One hundred fifteen ( $28 \%$ ) of the study participants were diagnosed for opportunistic infection before initiation of HAART and after confirmation of HIV infection (Table 2).

\section{Rate of regimen change}

Four hundred ten study subjects who were followed for different period gave a total of 10436.2 person months (869.68 person years) of observation. Within a follow up period, a total of $88(21.5 \%)$ of patients were changed their initial regimen. This makes the overall rate of initial regimen change 10.11/100 PY (95 \% CI 8.29, 12.6 PY). Regarding to the time of initial regimen change, 53 (60.2\%), 63 $(71.6 \%)$ and $80(90.9 \%)$ were changed their regimen within 6 months, 1 year and 3 years respectively, the remaining 8 (9.1\%) were changed after 3 years of follow up. The cumulative probability of surviving on initial regimen at the end of 6 months was 0.83 ; at the end of 1 years 0.81 ; at the end of 3 years 0.73 and the end of follow up was 0.7 (Fig. 1). Among the reasons for regimen change, side effect was the commonest reason which accounts for 62 (70.45\%) of cases and contribute for the 7.13/100PY. Tuberculosis 18 (20.45\%), pregnancy 4 (4.5\%), virological failure $3(3.4 \%)$ and occurrence of hepatitis $\mathrm{B}$ with chronic liver diseases 1 $(1.14 \%)$ were other reasons for regimen change. The commonest side effect for regimen change was found to be anemia 33 (53.2 \%), followed by rash 14 (22.6\%) (Table 3).

\section{Predictor of regimen change}

In the multivariate Cox-regression analysis, baseline WHO clinical stage, co-medication with ART, occurrence of $\mathrm{TB}$ and side effect on initial regimen remained a significant predictor of the initial regimen change. Accordingly, HIV patients who were stage III at initiation of HAART increased the risk of initial regimen change by 1.92 times when compared to those who were stage I/II at any time $(\mathrm{AHR}=1.92,95 \% \mathrm{CI} 1.12,3.35)$. Those who 
Table 2 Baseline clinical and immunological status of HIV positive adults at initiation of HAART, University of Gondar Referral Hospital from January 2010 to December $2014(n=410)$

\begin{tabular}{|c|c|c|}
\hline Characteristics & Frequency & Percent \\
\hline \multicolumn{3}{|l|}{ Initial regimen } \\
\hline AZT-3TC-NVP & 177 & 43.2 \\
\hline TDF-3TC-EFV & 147 & 35.9 \\
\hline AZT-3TC-EFV & 37 & 9 \\
\hline TDF-3TC-NVP & 28 & 6.8 \\
\hline D4T(30)-3TC-NVP & 16 & 3.9 \\
\hline D4T(30)-3TC-EFV & 3 & 0.7 \\
\hline ABC-3TC-EFV & 2 & 0.5 \\
\hline \multicolumn{3}{|c|}{ Number of ART pill/day } \\
\hline One & 128 & 31.2 \\
\hline Two & 201 & 49 \\
\hline Three & 40 & 9.8 \\
\hline Four & 41 & 10 \\
\hline \multicolumn{3}{|l|}{ CPT prophylaxis } \\
\hline Yes & 401 & 97.8 \\
\hline No & 9 & 2.2 \\
\hline \multicolumn{3}{|c|}{ Past OI before HARRT initiation } \\
\hline No & 295 & 72 \\
\hline Yes & 115 & 28 \\
\hline \multicolumn{3}{|l|}{ Functional status } \\
\hline Working & 361 & 88 \\
\hline Ambulatory & 29 & 7.1 \\
\hline Bed ridden & 20 & 4.9 \\
\hline \multicolumn{3}{|l|}{ WHO clinical stage } \\
\hline 1 & 105 & 25.6 \\
\hline$\|$ & 73 & 17.8 \\
\hline III & 172 & 42 \\
\hline IV & 60 & 14.6 \\
\hline \multicolumn{3}{|l|}{ CD4 count } \\
\hline$<100$ cell/mm $/ \mathrm{mm}^{3}$ & 110 & 26.8 \\
\hline $100-199$ cell/mm³ & 150 & 36.6 \\
\hline 200-349 cell/mm³ & 133 & 32.4 \\
\hline$\geq 350 \mathrm{cell} / \mathrm{mm}^{3}$ & 17 & 4.1 \\
\hline \multicolumn{3}{|l|}{ Baseline Hgb } \\
\hline$<7 \mathrm{~g} / \mathrm{dl}$ & 8 & 2 \\
\hline $7-9.9 \mathrm{~g} / \mathrm{dl}$ & 37 & 9 \\
\hline $10-12.9 \mathrm{~g} / \mathrm{dl}$ & 173 & 42.2 \\
\hline$\geq 13 \mathrm{~g} / \mathrm{dl}$ & 192 & 46.8 \\
\hline \multicolumn{3}{|l|}{ Base line weight } \\
\hline$<60 \mathrm{~kg}$ & 318 & 77.6 \\
\hline$\geq 60 \mathrm{~kg}$ & 92 & 22.4 \\
\hline
\end{tabular}

were developed TB on an initial regimen had about 8.33 times at higher risk of changing their initial regimen at any time as compared to those who did not develop TB $(\mathrm{AHR}=8.33,95 \% \mathrm{CI} 4.47,15.53)$ (Fig. 2).

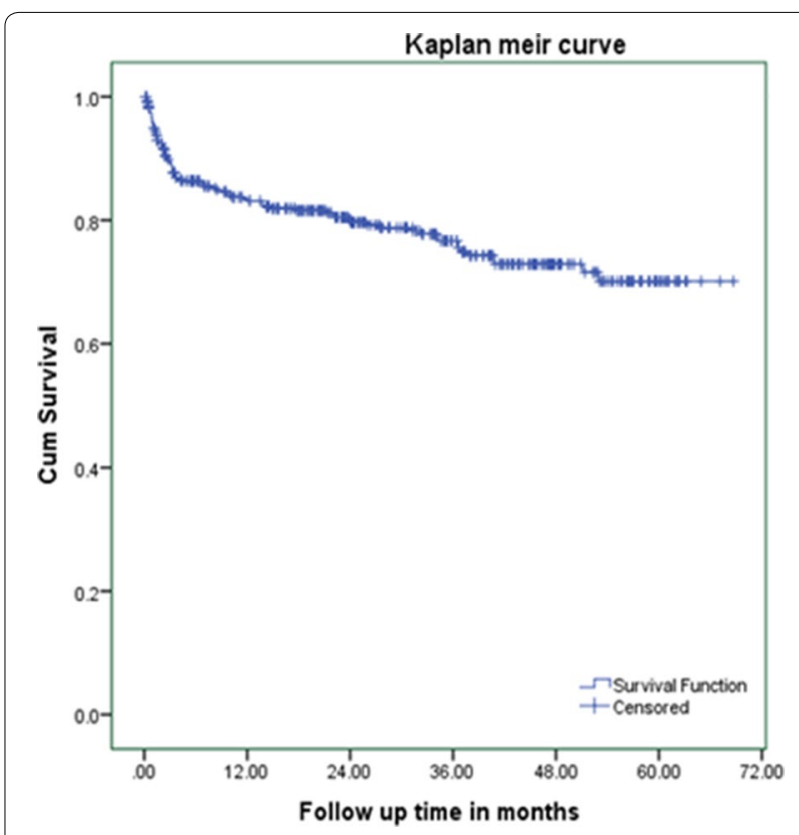

Fig. 1 Kaplan-Meir curve of surviving on initial regimen proportion for HIV positive adults on initial HAART at University of Gondar referral Hospitals, starting ART from January 12010 to June 2015)

Table 3 Common side effects among patients with regimen change at University of Gondar Referral Hospital from January 2010 to June $2015(n=88)$

\begin{tabular}{lll}
\hline Types of side effect & Frequency & Percent \\
\hline Anemia & 33 & 53.22 \\
Rash & 14 & 22.58 \\
Peripheral neuropathy & 9 & 14.51 \\
Nausea and vomiting & 5 & 8.06 \\
Abdominal pain & 4 & 6.45 \\
Depression & 3 & 4.83 \\
Lipoatropy & 2 & 3.22 \\
Fatigue & 2 & 3.22 \\
\hline
\end{tabular}

Patients on HAART who were taking other medication with ART had about 2.54 times at higher risk of changing their initial regimen at any time as compared to those who did not take other medication (AHR $=2.5,95 \% \mathrm{CI}$ 1.46, 4.39). Those who had ART drug side effect on initial regimen were 25.27 times at higher risk of changing their initial regimen as compared to those who had not side effect (AHR $=25.27,95 \%$ CI 15.12-42.00) (Table 4).

\section{Discussion}

The rate of initial regimen change among adult HIV patients on HAART was found to be 10.11/100PY (95\% CI 8.29, 12.6 PY). This finding is lower than a study 


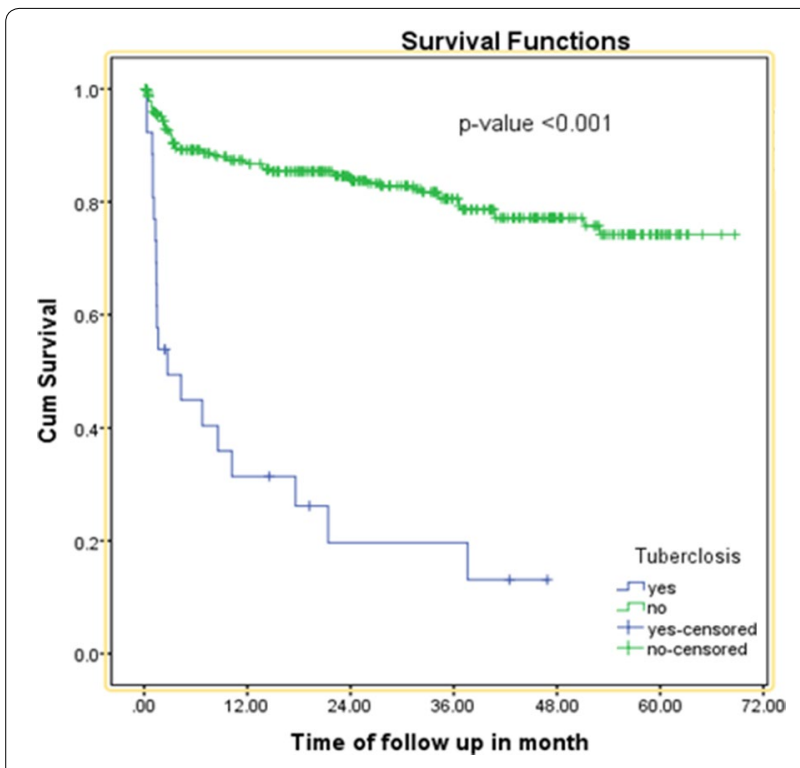

Fig. 2 Kaplan-Meier curve of surviving on initial regimen proportion based on the occurrence of tuberculosis on initial regimen in University of Gondar Referral Hospital from January 2010 to June 2015

conducted in Thailand 13.8/100PY [8], multicenter study in North America and Europe 14.4/100PY [7], Brazil 28.3/100PY [10] and Swiss 41.5/100PY [9]. This might be explained by the difference in defining outcome variables, since in our case we did not considered treatment discontinuation as regimen change unless they restart with different regimen. Furthermore, limited combined antiretroviral options or WHO based guideline in our setting may limit the clinician decision on cART modification. The other possible reasons might be regular monitoring of viral load for treatment response in developed countries might pick virological failure earlier which calls the need for regimen change.

Similarly, it is lower than studies done in West Africa and Kenya with a rate of $16.2 / 100 \mathrm{PY}$ and $18.6 / 100 \mathrm{PY}$ respectively $[11,12]$. This might be due to the difference in follow up period 15 and 10.7 months in West Africa and Kenyan study but 23.28 months for our study. In addition to this our study include participants who started HAART after 2010 in which WHO recommended to phase out D4T but West Africa and Kenyan studies were done before 2011 which might overestimate the rate.

In this study, being in WHO clinical stage III at initiation of ART, occurrence of TB on initial regimen, comedication with ART and side effect on initial regimen were found to be predictors of regimen change.

Those who had started HAART at baseline WHO clinical stage III were nearly two times at higher risk of changing their initial regimen as compared to those with
Table 4 Bivariate and multivariable Cox regression analysis for predictors of initial HAART regimen change among adult HIV positive patients at University of Gondar Referral Hospital, January 2010 to June, 2015 ( $n=410$ )

\begin{tabular}{|c|c|c|c|c|}
\hline \multirow[t]{2}{*}{ Variable } & \multicolumn{2}{|c|}{ Survival status } & \multirow{2}{*}{$\begin{array}{l}\text { Crude HR } \\
(95 \% \mathrm{Cl})\end{array}$} & \multirow{2}{*}{$\begin{array}{l}\text { Adjusted HR } \\
(95 \% \mathrm{Cl})\end{array}$} \\
\hline & Event & Censored & & \\
\hline \multicolumn{5}{|l|}{ Weight } \\
\hline$<60 \mathrm{~kg}$ & 56 & 262 & 1.00 & 1.00 \\
\hline$\geq 60 \mathrm{~kg}$ & 32 & 60 & $1.91(1.24-2.95)$ & $1.19(0.70-2.03)$ \\
\hline \multicolumn{5}{|c|}{ Baseline WHO stage } \\
\hline $\begin{array}{c}\text { Stage } \\
|/ /|\end{array}$ & 23 & 155 & 1.00 & 1.00 \\
\hline Stage III & 50 & 122 & $2.45(1.49-4.01)$ & $1.92(1.12-3.31)^{*}$ \\
\hline Stage IV & 15 & 43 & $1.945(1.01-3.73)$ & $0.55(0.25-1.18)$ \\
\hline \multicolumn{5}{|c|}{ TB on initial regimen } \\
\hline Yes & 20 & 6 & $7.92(4.76-13.16)$ & $8.33(4.47-15.53)^{*}$ \\
\hline No & 68 & 316 & 1.00 & 1.00 \\
\hline \multicolumn{5}{|c|}{ Initial NRTI backbone } \\
\hline $\begin{array}{l}\text { TDF/ } \\
\text { ABC }\end{array}$ & 26 & 151 & 1.00 & 1.00 \\
\hline $\begin{array}{l}\text { AZT/ } \\
\text { D4T }\end{array}$ & 62 & 171 & $1.68(1.06-2.65)$ & $072(0.40-1.28)$ \\
\hline \multicolumn{5}{|c|}{ Initial NNRTI } \\
\hline NVP & 60 & 161 & $1.84(1.17-2.88)$ & $1.74(0.79-3.84)$ \\
\hline EFV & 28 & 161 & 1.00 & 1.00 \\
\hline \multicolumn{5}{|c|}{ Co-medication with ART other than CPT } \\
\hline Yes & 32 & 52 & $2.68(1.74-4.15)$ & $2.54(1.46-4.39)^{*}$ \\
\hline No & 56 & 270 & 1.00 & 1.00 \\
\hline \multicolumn{5}{|c|}{ Side effect } \\
\hline Yes & 63 & 9 & $18.93(11.82-30.29)$ & $25.27(15.12-42)^{*}$ \\
\hline No & 25 & 313 & 1.00 & 1.00 \\
\hline
\end{tabular}

* Statistically significant at $p$ value $<0.05$

WHO clinical stage I/II. This finding is in line with studies done in Switzerland and two Kenyan studies [12, 15, 16]. This might be due to the fact that those patients who had advanced disease are likely to be on other medications which might result in drug interaction, side effect which in turns result in drug change. In contrary with other most studies, in this study WHO clinical stage IV were not a predictors for initial regimen change. The possible reason might be, low survival of patient on stage four which may result in death before the occurrence of the event.

Those who had co-medication with HAART were nearly two and half times increase the hazard of changing their initial regimen at any time as compared to those who did not take other medication. This is supported by Swiss HIV cohort and Ethiopian study at Mekelle hospital $[9,18]$. The possible reason might be drug-drug interaction and overlapping toxicity between ART drugs and other medication. The other possible explanation 
might be poly pharmacy which could lead to poor adherence due to pill burden which in turn resulted in poor efficacy of treatment result in drug change secondary to treatment failure.

Those who had side effect on the initial regimen were nearly twenty five times increased the hazard of changing their initial regimen at any given time as compared to those who did not develop side effect. This finding is supported by studies done in India, Nigeria and Ethiopia [14, $18,19]$. This is due to the fact that the occurrence of side effect alter the quality of life and even result in a death of a patient and it is a short term predictor for regimen change specially for grade III and IV toxicity but WHO recommend to follow the side effect cautiously for grade I and II toxicity before regimen change [5].

Those who had developed TB on initial regimen were nearly eight times at higher risk of changing their initial regimen at any time as compared to those who did not develop TB. This study is supported with a study done in India [19] and another literatures put it as one of the major reasons for regimen change [2, 12, 15]. In fact, tuberculosis is one of the opportunistic infection that occurs at any CD4 count in HIV patient, it might predicts clinical failure if it occurs after 6 months of initiation of ART which subsequently indicate the need of treatment change [11]. The other reason is the enzyme inducer nature of TB drugs specially Rifampicin induces cytochrome 450 enzyme that facilitate the metabolic activity of liver which makes under therapeutic level of ART drugs specially NVP which result in viral resistance, this calls for the need of regimen change when TB develop [5].The other explanation might be the pill burden result in poor adherence and its common toxicity with ART drugs result in the need for change [20].

Because of the retrospective nature of the study some important predictors which had a significant association with initial regimen change in other studies, like BMI and hepatitis $B$ and $C$ infection were missed.

\section{Conclusions}

Rate of initial regimen change was found to be high and most of the change occurred within a year after initiation of HAART. Having WHO clinical stage III at initiation of ART, occurrence of TB on initial regimen, co-medication with ART and side effect up on initial regimen were found to be predictors of regimen change. Therefore, it is important to give special attention for patients who have advanced disease and taking additional medication. Strengthening care full follows up and screening for side effect and tuberculosis is important.

\section{Abbreviations}

ABC: abacavir; AHR: adjusted hazard ratio; AIDS: acquired immunodeficiency syndrome; AZT: azidothyamidine; Cart: combined antiretroviral therapy; CHR: crude hazard ratio; Cl: confidence interval; D4T: stavudine; EFV: efavirenz; HAART: highly active anti-retroviral therapy; HGB: hemoglobin; HIV: human immunodeficiency virus; IQR: interquartile range; NVP: nevirapine; OI: opportunistic infection; PLWHIV: people living with HIV; PY: persons years; SPSS: statistical package for social science; TB: tuberculosis; TDF: tenofovir; UNAIDS: Joint United Nation Program on HIV/AIDS; WHO: World Health Organization; 3TC: lamivudine.

\section{Authors' contributions}

DZ conceived the idea and wrote the proposal, participated in data collection process, analyze date and draft the paper. BA and ZA approved the proposal with some revisions, participated in data analysis and reviewed the manuscript. All authors read and approved the final manuscript.

\section{Author details}

${ }^{1}$ Department of Nursing, College of Medicine and Health Science, University of Gondar, Gondar, Ethiopia. ${ }^{2}$ Department of Internal Medicine, College of Medicine and Health Science, School of Medicine, University of Gondar, Gondar, Ethiopia. ${ }^{3}$ Department of Epidemiology and Biostatistics, College of Medicine and Health Science, Institute of Public Health, University of Gondar, Gondar, Ethiopia.

\section{Acknowledgements}

The authors would like to thank the data collectors for their collaboration during the data collection. We would also like to thank University of Gondar for providing ethical clearance.

\section{Competing interests}

The authors declare that they have no competing interests.

Received: 28 October 2015 Accepted: 4 February 2016

Published online: 17 February 2016

\section{References}

1. Rappold M, Rieger A, Steuer A, Geit M, Sarcletti M, Haas B, et al. Treatment modification in HIV-infected individuals starting antiretroviral therapy between 2011 and 2014. J Int AIDS Soc. 2014;17(4 Suppl 3):19768.

2. Jima YT. MT, ANGAMO, WABE N-T. Causes for antiretroviral regimen change among HIV/AIDS patients in Addis Ababa, Ethiopia. Tanzan J Health Res. 2013;15(1):1-9.

3. Chen RY, Westfall AO, Mugavero MJ, Cloud GA, Raper JL, Chatham AG, et al. Duration of highly active antiretroviral therapy regimens. Clin Infect Dis. 2003;37(5):714-22.

4. Blanco J, Clotet B. Learning from drug changes in antiretroviral therapy. AIDS. 2013;27(5):833-4.

5. Ministry of Health. National Comprehensive HIV Care and Treatment Training for Health care Providers. Ethiopia; 2014.

6. Orrell C, Harling G, Lawn SD, Kaplan R, McNally M, Bekker LG, et al. Conservation of first-line antiretroviral treatment regimen where therapeutic options are limited. Antivir Ther. 2007;12(1):83-8.

7. Abgrall S, Ingle SM, May MT, Costagliola D, Mercie P, Cavassini M, et al. Durability of first ART regimen and risk factors for modification, interruption or death in HIV-positive patients starting ART in Europe and North America 2002-2009. AIDS. 2013;27(5):803-13.

8. Tsuchiya N, Pathipvanich P, Wichukchinda N, Rojanawiwat A, Auwanit W, Ariyoshi K, et al. Incidence and predictors of regimen-modification from first-line antiretroviral therapy in Thailand: a cohort study. BMC Infect Dis. 2014;14(1):565,

9. Elzi L, Marzolini C, Furrer H, Ledergerber B, Cavassini M, Hirschel B, et al. Treatment modification in human immunodeficiency virus-infected individuals starting combination antiretroviral therapy between 2005 and 2008. Arch Intern Med. 2010;170(1):57-65. 
10. Cardoso SW, Grinsztejn B, Velasque L, Veloso VG, Luz PM, Friedman RK, et al. Incidence of modifying or discontinuing first HAART regimen and its determinants in a cohort of HIV-infected patients from Rio de Janeiro. AIDS Res Hum Retrovir. 2010;26(8):865-74.

11. Landier J, Akonde A, Pizzocolo C, Haidara I, Drabo M, Pizarro L, et al. Switch to second-line ART in West African routine care: incidence and reasons for switching. AIDS Care. 2011;23(1):75-8.

12. Inzaule S, Otieno J, Kalyango J, Nafisa L, Kabugo C, Nalusiba J, et al. Incidence and predictors of first line antiretroviral regimen modification in western Kenya. PLoS One. 2014;9(4):e93106.

13. Gebremedhin $L$, Birhane A. Reasons for anti-retroviral regimen changes in HIV/AIDS patients of Ayder Referral Hospital ART clinic, Mekelle, Ethiopia. Int J Pharma Sci Res. 2014;5(0975-9492):693-700

14. Abah IO, Darin KM, Ebonyi AO, Ugoagwu P, Ojeh VB, Nasir N, et al. Patterns and predictors of first-line antiretroviral therapy modification in HIV1-infected adults in a large urban outpatient cohort in Nigeria. J Int Assoc Provid AIDS Care. 2015;14(4):348-54.

15. Takuva S, Louwagie G, Zuma K, Okello V. Durability of first line antiretroviral therapy: reasons and predictive factors for modifications in a Swaziland cohort. Antivir Antiretrovir. 2012;4(1):014-20.
16. Owuor A, Lule G, Otieno C, Omonge E, Maritim M, Memiah P. Modification of antiretroviral therapy in a cohort study of HIV-infected patients attending an urban teaching Hospital in Kenya. Int J Virol AIDS. 2014;1:003.

17. Ohene SA, Addo NA, Zigah F, Newman M, Lartey M, Romero MA, et al. Evaluation of antiretroviral therapy (ART) provision in an early cohort of patients initiating ART in Ghana. Pan Afr Med J. 2013;16:117.

18. Bayou T, Woldu M, Meskel GG, Mezgebe H. Factors determinant for change of initial antiretroviral treatment regimen among patients on ART follow-up clinic of Mekelle Hospital, Mekelle, Ethiopia. Int J Basic Clin Pharmacol. 2014;3(1):44-9.

19. Sandeep B, Chavan VR, Raghunandan M, Arshad M, Sayana SB. Factors influencing the substitution of antiretroviral therapy in human immunodeficiency virus/acquired immunodeficiency syndrome patients on first line highly active antiretroviral therapy. Asian J Pharm Clin Res. 2014;7(5):117-20.

20. Hill S, Kavookjian J, Qian J, Chung A, Vandewaa J. Effects of pill burden on discontinuation of the initial HAART regimen in minority female patients prescribed 1 pill/day versus any other pill burden. AIDS Care. 2014;26(5):595-601.

\section{Submit your next manuscript to BioMed Central and we will help you at every step:}

- We accept pre-submission inquiries

- Our selector tool helps you to find the most relevant journal

- We provide round the clock customer support

- Convenient online submission

- Thorough peer review

- Inclusion in PubMed and all major indexing services

- Maximum visibility for your research

Submit your manuscript at www.biomedcentral.com/submit
() Biomed Central 